\title{
Sex, Temperament, and Family Context: How the Interaction of Early Factors Differentially Predict Adolescent Alcohol Use and Are Mediated by Proximal Adolescent Factors
}

\author{
Linnea R. Burk \\ University of Wisconsin School of Medicine and Public Health \\ and University of Wisconsin-Madison
}

H. Hill Goldsmith

University of Wisconsin-Madison

\author{
Jeffrey M. Armstrong \\ University of Wisconsin School of Medicine and Public Health \\ Marjorie H. Klein \\ University of Wisconsin School of Medicine and Public Health \\ Marilyn J. Essex \\ University of Wisconsin School of Medicine and Public Health
}

\begin{abstract}
Adolescent alcohol use is common and has serious immediate and long-term ramifications. While concurrent individual and context factors are robustly associated with adolescent alcohol use, the influence of early childhood factors, particularly in interaction with child sex, are less clear. Using a prospective community sample of 362 (190 girls), this study investigated sex differences in the joint influence of distal childhood and proximal adolescent factors on Grade 10 alcohol use. All risk factors and two-way early individual-by-context interactions, and interactions of each of these with child sex, were entered into the initial regression. Significant sex interactions prompted the use of separate models for girls and boys. In addition to the identification of early (family socioeconomic status, authoritative parenting style) and proximal adolescent (mental health symptoms, deviant friends) risk factors for both girls and boys, results highlighted important sex differences. In particular, girls with higher alcohol consumption at Grade 10 were distinguished by the interaction of early temperamental disinhibition and exposure to parental stress; boys with higher alcohol consumption at Grade 10 were distinguished primarily by early temperamental negative affect. Results have implications for the timing and type of interventions offered to adolescents.
\end{abstract}

Keywords: adolescent, alcohol, individual-context interaction, early risk factors, prevention

Alcohol use is a serious problem among youth and is associated with a wide range of negative outcomes including mental health problems (Kandel et al., 1997), behavioral and academic problems (Englund, Egeland, Oliva, \& Collins, 2008; Hawkins, Catalano, \& Miller, 1992), physical injury and mortality (Soderstrom \& Dearing-Stuck, 1993), and the use of other substances (Duncan, Duncan, Biglan, \& Ary, 1998). Approximately 55\% of U.S. adolescents in 8th, 10th, and 12th grades have tried alcohol (Johnston, O'Malley, Bachman, \& Schulenberg, 2009), and approximately $28 \%$ aged 12 to 20 years have consumed alcohol in the past month
(Johnston et al., 2009; Wright, Sathe, \& Spagnola, 2007). Among adults, males drink more and more frequently (Substance Abuse Mental Health Services Administration, 2002; Wilsnack, Vogeltanz, Wilsnack, \& Harris, 2000) [in part attributable to physiology (Ammon, Schafer, Hofmann, \& Klotz, 1996; Frezza et al., 1990)], but among younger adult cohorts, females' use has increased (Babor \& Winstanley, 2008; Pritchard \& Cox, 2007). Further, adult females are twice as likely to exceed safer alcohol consumption guidelines (Lande, Marin, Chang, \& Lande, 2007) [two drinks per day for men; one drink per day for women (National Institute
Linnea R. Burk, Department of Psychiatry, University of Wisconsin School of Medicine and Public Health, and Department of Psychology, University of Wisconsin-Madison; Jeffrey M. Armstrong, Marjorie H. Klein, and Marilyn J. Essex, Department of Psychiatry, University of Wisconsin School of Medicine and Public Health; H. Hill Goldsmith, Department of Psychology, University of Wisconsin-Madison; Timothy J. Strauman and Phillip Costanzo, Department of Psychology and Neuroscience, Duke University.

The authors wish to express their appreciation to the families and teachers who have so generously committed their time to the project and to the dedicated staff of the Wisconsin Study of Families and Work. The authors also wish to express their appreciation to Dr. Chongming Yang of Duke University for his assistance and statistical consultation. This work was supported by National Institute of Mental Health Grants R01MH44340, P50-MH052354, and P50-MH069315, P50-MH084051; the John D. and Catherine T. MacArthur Foundation Research Network on Psychopathology and Development; the University of Madison School of Medicine and Public Health; the Graduate School of the University of Wisconsin-Madison; and National Institute on Drug Abuse Grant P20DA017589 (PI, Kenneth Dodge) and P30-DA023026 (PI, Philip Costanzo) awarded to the Duke University Transdisciplinary Prevention Research Center.

Correspondence concerning this article should be addressed to Linnea R. Burk, Department of Psychiatry, University of Wisconsin School of Medicine and Public Health, Madison, WI 53719. E-mail: burk@ wisc.edu 
on Alcohol Abuse and Alcoholism, 2008)]. Importantly for both males and females, adolescent alcohol use predicts adult problem use (Englund et al., 2008; Pitkanen, Kokko, Lyyra, \& Pulkkinen, 2008), including alcoholism (Grant \& Dawson, 1997), while delaying the onset or regular use of alcohol enhances well-being (Grant \& Dawson, 1997; Hawkins, Catalano, Kosterman, Abbott, \& Hill, 1999). Such findings suggest differential consequences of alcohol use by sex and level of use during adolescence.

Previous studies support multiply determined paths to adolescent alcohol use influenced by diverse individual and contextual factors over time and have led to the application of epigenetic theory to alcohol research [e.g., (Moss, Vanyukov, Yao, \& Kirillova, 1999; Tarter, Blackson, Brigham, Moss, \& Caprara, 1995; Tarter \& Vanyukov, 1994)]. Within the epigenetic perspective early traits and behaviors are organized into increasingly complex systems, called derivatives, through maturation and interaction with the environment. The level of organization achieved in each developmental period also influences future outcomes. Thus the effects of early attributes and experiences are mediated by derivatives (such as psychopathology or peer selection) (Tarter \& Vanyukov, 1994; Wills, Sandy, \& Yaeger, 2000), and this patterning of risk factors contributes differentially to the likelihood of alcohol use. From this perspective, a developmental model of adolescent alcohol use should include early individual and contextual factors, their interactions, and proximal adolescent factors likely to be derivatives.

\section{Early Individual and Context Factors}

Individual traits, such as temperament, influence exposure to environmental risk by predisposing individuals toward certain behaviors and social contexts (Silberg, Rutter, D'Onofrio, \& Eaves, 2003). Two pathways to adult alcoholism grounded in early temperament have been proposed (Zucker, Donovan, Masten, Mattson, \& Moss, 2008), one progressing from disinhibition or irritability to externalizing and antisocial behaviors, and the other from negative affect to later experiences of depression and anxiety. Childhood disinhibition and undercontrol (Caspi, Moffitt, Newman, \& Silva, 1996; Dubow, Boxer, \& Huesmann, 2008; Kirisci, Tarter, Mezzich, \& Vanyukov, 2007) increase risk for adolescent alcohol use and alcohol use disorders. Greater adolescent negative affect (Wills, Sandy, Shinar, \& Yaeger, 1999) and childhood inhibition and anxiety (Caspi et al., 1996; Hawkins et al., 1999) have been associated with heavier drinking and support early temperamental negative affect as a potential risk factor.

A number of childhood family context variables have been associated with adolescent alcohol use. Adolescents exhibit earlier onset and more serious use patterns when parents drink (Guo, Hawkins, Hill, \& Abbott, 2001; Hayatbakhsh et al., 2008; Kirisci et al., 2007; Wills, Sandy, Yaeger, \& Shinar, 2001). This association is attributable, in part, to behavioral modeling (Alati et al., 2005; Guo et al., 2001) and increased access to alcohol (Hearst, Fulkerson, Maldonado-Molina, Perry, \& Komro, 2007; Tobler, Komro, \& Maldonado-Molina, 2009). Discrete parenting behaviors in early adolescence also play a role. Lax rules and poor parental monitoring predict greater alcohol use at age 21 (Guo et al., 2001), whereas adolescent authoritative parenting predicts less alcohol use and fewer alcohol problems (Johnson \& Johnson, 2001; van der Vorst, Engels, Meeus, Dekovic, \& Vermulst, 2006).
Parental involvement and warmth strengthen social bonds (Catalano, Kosterman, Hawkins, \& Newcomb, 1996), and warm and/or more egalitarian parent-child relations may discourage or limit the opportunity for association with deviant peers (Suldo, Mihalas, Powell, \& French, 2008). It is less clear how authoritative parenting experienced earlier during childhood influences use of alcohol in adolescence.

Other aspects of the childhood and preadolescent family environment such as instability, negative or conflicted parent-child relations, harsh discipline (Hayatbakhsh et al., 2008; Maggs, Patrick, \& Feinstein, 2008; Wills et al., 2001), parental depression, and negative life events (Weissman et al., 2006; Wills et al., 2001) increase risk for the initiation and persistence of adolescent alcohol use. Socioeconomic status (SES) has been equivocally associated with both more and less use (Hanson \& Chen, 2007; Tobler, Komro, \& Maldonado-Molina, 2009; Trim \& Chassin, 2008). Further, multiple negative factors likely increase overall family stress and suggest psychosocial stress itself as a potential risk. Supporting this assertion are associations of concurrent stress with adult and adolescent alcohol use (De Bellis, 2002), prediction of adolescent use by preadolescent family stress (Ennett et al., 2008), and prediction of early initiation and problem use by childhood maltreatment (Galaif, Stein, Newcomb, \& Bernstein, 2001; Hamburger, Leeb, \& Swahn, 2008; Kaufman et al., 2007). Extensive research implicates childhood stress exposure to the development of mental health and behavior problems (Essex, Klein, Cho, \& Kalin, 2002b; Hammen, Brennan, \& Shih, 2004; Kaplow \& Widom, 2007), although few studies have used broad measures of early stress to predict adolescent alcohol use.

\section{Proximal Individual and Context Factors}

Epigenetic theory posits that proximal risk factors mediate the influence of distal factors such that developmental pathways rooted in early temperamental negative affect and disinhibition are likely mediated by derivative adolescent mental health problems (Zucker et al., 2008). Early temperamental traits are differentially associated with later mental health; greater early disinhibition and impulsivity predict externalizing (Frick \& Morris, 2004; Leve, Kim, \& Pears, 2005), while greater early negative affect and inhibition predict internalizing (Caspi, Henry, McGee, Moffitt, \& Silva, 1995; Leve, Kim, \& Pears, 2005). Others have found childhood and adolescent externalizing (Alati et al., 2005; Englund et al., 2008; Niemela et al., 2006) and internalizing (Hussong, Curran, \& Chassin, 1998; Reinherz, Giaconia, Hauf, Wasserman, \& Paradis, 2000) to increase risk for substance use, abuse, and dependence.

Additionally, an adolescent's peers greatly influence alcohol use. Teens with deviant friends (Duncan et al., 1998) and friends who drink (Fergusson, Horwood, \& Lynskey, 1995; Kuntsche \& Jordan, 2006) are more likely to use and abuse alcohol (Costa, Jessor, \& Turbin, 1999). Younger teens with older (Kuntsche, Gmel, Wicki, Rehm, \& Grichting, 2006) or opposite sex friends (Malow-Iroff, 2006) are at greater risk, particularly girls who associate with older boys (Dick et al., 2007; Gaughan, 2006). Selection of or by a peer group is largely derivative of early individual characteristics in interaction with the social environment. Thus, the influence of adolescent peers is apt to mediate a range of childhood factors (Suldo et al., 2008). 


\section{Sex}

Independent studies have observed significant sex differences in most risk factors for adolescent alcohol use (Dick et al., 2007; Englund et al., 2008; Gaughan, 2006), in the association of early temperament to later psychopathology (Leve, Kim, \& Pears, 2005), and in the incidence of adolescent mental health symptoms (Zahn-Waxler, Shirtcliff, \& Marceau, 2008). Further, the physiological effects of alcohol (Ammon et al., 1996; Frezza et al., 1990), patterns of use (Keyes, Grant, \& Hasin, 2008; Pritchard \& Cox, 2007), and motivations for use (Kuntsche, Knibbe, Gmel, \& Engels, 2006) differ by sex among adults. Because of the extensive differences in these variables, it is likely girls and boys will exhibit different patterns of early individual-context interactions and mediation of early factors by adolescent constructs.

\section{Present Study}

Although a wealth of research has established numerous proximal risk factors for adolescent alcohol use, few studies have considered early individual risk factors, especially in interaction with the developmental context (Pitkanen et al., 2008; Zucker et al., 2008). Further, longitudinal studies have focused primarily on context factors alone (Hayatbakhsh et al., 2008; Schulenberg \& Maggs, 2008), and most have studied children of alcoholic parents (Hawkins et al., 1997; Wong et al., 2006). Research with prospective community samples would broaden the understanding of adolescent alcohol use and benefit health policy by reaching beyond immediate adolescent causes (Babor \& Winstanley, 2008). The identification of childhood factors and individual-by-context interactions may be salient to defining higher-risk subgroups, to understanding why some teens are more vulnerable to proximal influences, and to the refinement of intervention strategies. The present study tests a unique developmental model predicting level of adolescent alcohol use in a prospective community sample. Supporting the epigenetic perspective, we selected the individual factors of child sex and two early temperamental traits (disinhibition, negative affect), three early family context factors (parental stress, parental alcohol use, authoritative parenting style), and three potential adolescent mediators (internalizing, externalizing, deviant friends). Adolescent alcohol use was measured in Grade 10 (i.e., around age 16), when population-based studies suggest significant numbers of adolescents consume alcohol but rates of problem use remain low (Johnston et al., 2009).

Greater temperamental disinhibition and negative affect were expected to predict greater alcohol use and mental health problems. Because of known sex differences, disinhibition and externalizing symptoms were expected to have greater salience for boys' alcohol use, and negative affect and internalizing symptoms for girls'. With regard to family context, parental alcohol use was expected to be positively and authoritative parenting style negatively related to adolescent alcohol use. Because many family context factors are inter-correlated, a composite stress factor, developed in previous work (Essex et al., 2002b) representing longterm stress exposure, was included. Greater family stress was expected to predict alcohol use. Epigenetic theory stresses the import of emergent factors, but it was not known which individualby-context interactions would prove most salient. Thus, no specific hypotheses were offered.
Finally, adolescent factors likely to be derivatives-i.e., mental health symptoms and deviant friends-were included as possible mediators. Consistent with past work, mental health symptoms (particularly externalizing) and deviant friends were expected to predict alcohol use and to mediate distal factors and interactions. Family SES and Grade 9 alcohol use were controlled in all models. The age and sex makeup of adolescent peer groups were assessed for moderating effects. By using prospective, longitudinal data, the present study sought to contribute new knowledge of early risk factors, the relationship of distal factors to proximal factors, and the role of individual-context interactions in predicting adolescent alcohol use.

\section{Method}

\section{Participants}

A total of 760 women and their husbands/partners were initially contacted during the second trimester of pregnancy through obstetric/ gynecology and low-income clinics around Milwaukee (80\%) and Madison (20\%), Wisconsin, for participation in the Wisconsin Maternity Leave and Health Project (now called the Wisconsin Study of Families and Work, WSFW). Because the project originally focused on maternal employment, family stress, and mental health during the first postnatal year, female participants met the following inclusion criteria: (a) over age 18; (b) living with the biological father; (c) at least one member of the couple working for pay; (d) not a student; and (e) not unemployed [see (Hyde, Klein, Essex, \& Clark, 1995) for details]. Of these, $25 \%$ refused or were screened out, yielding an initial sample of 570, of which 560 had eligible live births. At Grade 10, 384 (67\%) families remained in the study. The present analyses focused on 362 adolescents (190 girls, 172 boys) who reported on alcohol use at Grade 10. Average child age at Grade 10 was 16 years; $11 \%$ represented ethnic and/or racial minorities (89\% Caucasian, 4\% African American, 3\% Native American/Alaskan Native, 2\% Asian/Pacific Islander, 1\% Hispanic, 1\% Other). At recruitment (1990-1991), mothers' age ranged from 20 to 41 years $(M=30)$ and fathers' from 20 to 55 years $(M=32)$; $96 \%$ were married. Two percent of mothers had less than a high-school degree, $41 \%$ graduated high school, $37 \%$ graduated college, and $20 \%$ had post-college education; fathers' education levels were similar. Annual family income ranged from $\$ 9,000$ to more than $\$ 200,000(M d n=\$ 48,000)$. There were no differences in demographic variables between the 362 families and the remainder of the original 570 with minor exceptions: participating parents were one year older (participating mothers $M=$ 29.72, $S D=4.33$, non-participating mothers $M=28.75, S D=$ 4.36, $t(568)=-2.57, p=.010$; participating fathers $M=31.65$, $S D=5.18$, non-participating fathers $M=30.63, S D=4.79$, $t(548)=-2.27, p=.024)$; and more participating couples were married $\left[\mathrm{P}=96 \%\right.$; $\left.\mathrm{NP}=92 \% ; \chi^{2}=7.32, d f(2), p=.026\right]$. A series of analyses of variance (ANOVAs) found no differences between participating and non-participating children in any putative risk factor. Parents and teachers gave informed consent at each time point; child assent was obtained beginning at Grade 7 in accordance with the policies of the University of Wisconsin Institutional Review Board. 


\section{Measures}

Early factors were assessed during the developmental periods of infancy (ages 1, 4, and/or 12 months), preschool (ages 31/2 and/or $41 / 2$ ), and late childhood (Grade 3). Proximal adolescent factors were assessed in Grades 7 and/or 9). Variables were constructed from available measures within these developmental periods. The outcome of adolescent alcohol use was assessed in Grade 10. Measures repeated at two assessments were averaged to form stable estimates and reduce the number of variables. Composite scores were generated using unrotated principle components analysis (PCA) which reduces the number of predictors and the risk of multicolinearity in predictive models by transforming correlated variables into fewer, uncorrelated principal components. The first component accounts for the majority of variability in the data, has greater variability than a simple average, and is retained as best representing the underlying construct (Dunteman, 1989). All variables were centered before analyses.

\section{Early Predictors}

Family SES. Family SES was composited from family income during the infancy and preschool periods as well as fathers' and mothers' education using PCA. The first component accounted for $56 \%$ of the variance.

Preschool temperamental disinhibition and negative affect. Temperament was assessed by mother report on the Children's Behavior Questionnaire [CBQ; (Rothbart, Ahadi, Hershey, \& Fisher, 2001)] at ages $3 \frac{1}{2}$ and $4 \frac{1}{2}$. Items were rated on a 7-point scale ranging from 1 (Extremely untrue of your child) to 7 (Extremely true of your child). Coefficients $\alpha$ were above .70 for subscales with "easy to read" behaviors such as Activity Level $\left(\alpha=.72\right.$ and .73 for ages $3 \frac{1}{2}$ and $4 \frac{1}{2}$, respectively), Approach $(\alpha=.71$ and .76), and Anger $(\alpha=.78$ and .78). Scales reflecting "harder to read" states such as Fear $(\alpha=.65$ and .73) and Sadness $(\alpha=.67$ and .63) were lower, an outcome not uncommon with collateral ratings of internal emotional experiences. Activity Level (e.g., "Child tends to run rather than walk") and Approach (e.g., "Child is very enthusiastic about things") were averaged to create Disinhibition scores. High scores characterize a bold child who approaches novelty and engages with the environment in a vigorous manner, the opposite of childhood inhibition. Disinhibition scores were correlated $(r=.74, p<.001)$; the average represented Preschool Temperamental Disinhibition. Negative Affect scores were created at ages $31 / 2$ and $41 \frac{1}{2}$ by PCA of Anger (e.g., "Child gets angry when can't find a play toy"), Fear (e.g., "Child is afraid of loud noises"), and Sadness (e.g., "Child is sometimes downcast for no reason"). The first factor accounted for $61 \%$ and $56 \%$ of the variance at ages $3 \frac{1}{2}$ and $4 \frac{1}{2}$, respectively. All subscales loaded at .62 or higher. Negative Affect scores were correlated $(r=.73, p<$ .001); the average represented Preschool Temperamental Negative Affect. While there is debate regarding whether negative affect characteristics (anger, fear, sadness, hostility, harm avoidance, depression, etc.) are best represented as a unitary construct (Watson, 2009) or individually (Ohannessian \& Hesselbrock, 2009), the use of PCA to create the current Preschool Temperamental Negative Affect variable maximizes the commonality of variance in this factor and reduces the differences (Dunteman, 1989).

Childhood authoritative parenting style. An Authoritative Parenting Style score was constructed using mothers' and fathers' responses to Likert-formatted items of the Child-Rearing Practices Report [CRPR; (Block, 1965)] administered at age 41/2 years and Grade 3. Items were rated on a 7-point scale ranging from 1 (Very true or like me) to 7 (Very untrue or not like me). Authoritative Parenting is characterized by clear rules and monitoring but also allows child independence (e.g., "I let my child make their own decisions"). Scores were correlated across time within reporter (Mother, $r=.59, p<.001$; Father, $r=.45, p<.001$ ); maternal and paternal scores were averaged separately. The maximum Authoritative Parenting Style score was used in analyses to increase variance and better represent high levels of this parenting style. Fathers $(184 ; 51 \%)$ and mothers $(178 ; 49 \%)$ contributed equally to the maximum scores.

Childhood parental alcohol use. A Parental Alcohol Use score was derived using three questions each about mothers' and fathers' use of alcohol. At child age $4 \frac{1}{2}$ and Grade 3, mothers answered two yes/no questions concerning their own and fathers' use of alcohol ("Do you/your partner drink alcohol daily?" and "Has anyone objected to your/your partner's drinking?"). Each "yes" response was assigned 1 point. At child age 41/2,19\% of fathers and $6 \%$ of mothers drank regularly; these percentages were $26 \%$ and $8 \%$, respectively at Grade 3 . At child age $41 / 2,18 \%$ of fathers and $3 \%$ of mothers experienced objections about their drinking, with similar percentages at Grade 3 (19\% of fathers and $3 \%$ of mothers). Mothers also reported the number of alcoholic drinks consumed on a daily basis for both themselves and fathers. At child age $4 \frac{1}{2}$, fathers' consumption ranged from 0 and 8 drinks daily $(M=0.75, S D=1.03)$; mothers' from 0 and 4 drinks daily $(M=0.35, S D=0.54)$. Reports were similar at Grade 3 for fathers (range $=0$ to $6, M=0.73, S D=1.05$ ) and mothers (range $=0$ to $4, M=0.33, S D=0.54)$.

Points were also assigned for the reported number of drinks consumed each day. The initial point for drinking was assigned taking into account guidelines for safer alcohol use (one drink per day for women, two drinks per day for men) (National Institute on Alcohol Abuse and Alcoholism, 2008). Thus parents who drank at "safer" levels received fewer points. Mothers received 1 point for $<1$ to 1 drink, 2 points for 2 drinks, 3 points for 3 drinks, and 4 points for 4 drinks. Fathers received 1 point for $<1$ to 2 drinks, 2 points for 3 drinks, 3 points for 4 drinks, 4 points for 5 drinks, 5 points for 6 drinks, 6 points for 7 drinks, and 7 points for 8 drinks. Points for all three items were summed across parent and across time to yield a total Parental Alcohol Use score $(M=3.36$, $S D=2.87$, range $=0-16)$, which was log transformed to normalize the distribution.

Childhood parental stress. Maternal and paternal stress scores were constructed separately from five domains: (1) depression symptoms, (2) family expressed anger, (3) parenting stress, (4) role overload, and (5) financial stress. The utility of similar composite stress scores has been shown in prior work (e.g., Ellis, Essex, \& Boyce, 2005; Essex, Klein, Slattery, Goldsmith, \& Kalin, 2010). Except when noted, infancy scores were averaged over the 1-, 4-, and 12-month assessments; preschool scores were averaged over the $3 \frac{1}{2} 2$ - and $4 \frac{1}{2}$-year-old assessments; late childhood scores were based on the Grade 3 assessment. (1) Depression symptoms were assessed by the Center for Epidemiologic Studies Depression scale [CES-D (Radloff, 1977); e.g., "I felt that I could not shake off the blues even with help from my family or friends"]. All coefficients $\alpha$ were greater than .85. (2) Family expressed anger in 
infancy was assessed with the average of three items from the Partner Role Quality scale tapping overt marital conflict [e.g., concerned about "arguing or fighting" (Barnett \& Marshall, 1989)]. In preschool and late childhood, PCA was used to combine the marital conflict scores with scores from the Anger Expression Inventory [STAXI (Spielberger, Krasner, Solomon, \& Janisse, 1988); e.g., "When angry or furious, I argue with others"] and the Negative subscale of the Family Expressiveness Questionnaire [FEQ (Halberstadt, 1986); e.g., "We blame one another for family troubles"]. All coefficients $\alpha$ were greater than .70. The first component accounted for more than $50 \%$ of the variance in both preschool and late childhood. (3) Parenting stress was calculated using PCA of the Competence and Child Reinforces Parent subscales of the Parenting Stress Inventory [PSI (Abidin, 1986); e.g., "I feel I cannot handle things"] and the average of three negative items (e.g., "I often feel angry with my child") from the CRPR (Block, 1965). In infancy, the CRPR was administered only at age 12 months. Coefficients $\alpha$ were greater than .65 for parent-child negativity, .75 for PSI Competence, and .65 for PSI Child Reinforces Parent across assessments. Each initial component accounted for more than $50 \%$ of the variance. (4) Role overload was calculated ( $z$ scores, averaged; $r=.48$ ) from the Role Restriction subscale of the PSI [e.g., "My child's needs control my life" (Abidin, 1986)] and the average of five items from the Role Overload scale [e.g., feeling "pulled apart by conflicting obligations" (Barnett \& Marshall, 1989)]; in infancy, Role Overload was assessed only at age 12 months. All coefficients $\alpha$ were greater than .75. (5) Financial stress was the average of four items (e.g., "how much difficulty making monthly payments"). All $\alpha$ were greater than .70 .

Separately for infancy, preschool, and late childhood, maternal and paternal reports of the five stress domains were combined using PCA. The first component of each PCA accounted for more than $50 \%$ of the variance; all stress domains had loadings greater than .50 for each period. ${ }^{1}$ The factor scores were correlated across time within reporter $(r \mathrm{~s}>.51$ for all periods, $>.64$ for adjacent periods, $p<0.001$ ); average maternal and paternal scores were calculated. The maximum parental score was used in analyses; mothers' scores comprised a slim majority (190; 53\%). To normalize its distribution, Childhood Parental Stress was log transformed.

\section{Proximal Predictors}

Adolescent mental health symptoms. Mental health symptoms were assessed using mother, teacher, and adolescent reports from the MacArthur Health and Behavior Questionnaire [HBQ (Boyce et al., 2002; Essex et al., 2002a)] at Grades 7 and 9. Mothers completed the HBQ as a telephone interview and teachers as a written questionnaire; adolescents completed a parallel questionnaire, the HBQ-Child (HBQ-C). For internalizing symptoms, mothers and teachers rated 16 or 18 items (in Grades 7 and 9, respectively) for Depression (e.g., "Cries a lot") and 12 or 14 items for Generalized Anxiety (e.g., "Worries about things in the future"). For externalizing symptoms, mothers and teachers rated nine items for Oppositional Defiant Disorder (e.g., "Argues a lot with adults"); 14 items for Conduct Disorder (e.g., "Lies or cheats"); seven or nine items for Inattention (e.g., "Does not seem to listen"); nine items for Impulsivity (e.g., "Interrupts or butts in on others"); four Overt Aggression items (e.g., "Gets in many fights"); and six Relational Aggression items (e.g., "Tries to get others to dislike a peer"). Items were rated on a 3-point scale ranging from 0 (never or not true) to 2 (often or very true). For the HBQ-C, adolescents completed 34 or 38 items (in Grades 7 and 9 , respectively) tapping internalizing symptoms (e.g., "I worry about things I've done/I don't worry about things I've done"); and 42 or 44 items tapping externalizing symptoms (e.g., "I do what adults ask me to do/I don't do what adults ask me to do"). To rate each item, adolescents first chose the statement from each pair that was most like them and then marked that statement as being "sort of like me," "mostly like me," or "really like me." Responses were coded on a 6-point scale based on which statement was selected (positive or negative) and whether the response was "really like $m e$ " (6 if positive, 1 if negative), "mostly like me" (5 if positive, 2 if negative), or "sort of like me" (4 if positive, 3 if negative). Coefficients $\alpha$ ranged from .70 to .96 across reporters and assessments.

PCA was used to combine mother, teacher, and adolescent reports into multi-informant scores for each construct, at each grade (Kraemer et al., 2003). The resulting scores accounted for more than $70 \%$ of the total variance. For some subjects, multiinformant scores were missing because of lack of one informant (23 Internalizing and 23 Externalizing in Grade 7; 41 Internalizing and 42 Externalizing in Grade 9). Missing values were replaced with scores constructed using available mother-adolescent (MA) or adolescent-teacher (AT) reports (there were no cases with mother and teacher, but not adolescent, reports). Alternate scores were highly correlated with multi-informant scores: all Internalizing $r \mathrm{~s}>.89$, all Externalizing $r \mathrm{~s}>.92$. Distribution of scores in Grade 7 for both Internalizing and Externalizing was 323 MTA, 19 MA, four AT, and 16 with multiple reporters missing. Distribution of scores at Grade 9 was 321 MTA, 34 MA, and seven AT for Internalizing; 320 MTA, 35 MA, and seven AT for Externalizing.

\footnotetext{
${ }^{1}$ For the two constructs (Preschool Temperamental Negative Affect and Childhood Parental Stress) derived from PCA that were not guided by the multi-informant theoretical perspective, competing confirmatory factor analytic models were constructed using SPSS Amos. For the one factor solution to Temperamental Negative Affect values indicated adequate fit: age 3.5, $\chi^{2}=0.2, p=.655$, and RMSEA $=.000$; age 4.5, $\chi^{2}=0.0, p=$ 1.0 , and RMSEA $=.000$. For Parental Stress a series of CFA's specifying one to five factors were run for each time period (infancy, preschool, late childhood) and each parent (mother, father).The fit indicators for Parental Stress showed greater variability: Mother Infancy $\chi^{2}=24.18, p=.000$, and RMSEA $=.103$; Mother Preschool $\chi^{2}=18.9, p=.002$, and RMSEA $=.088$; Mother Grade $3 \chi^{2}=1.7, p=.435$, and RMSEA $=.000$; Father Infancy $\chi^{2}=54.67, p=.000$, and RMSEA $=.166$; Father Preschool $\chi^{2}=16.8, p=.005$, and RMSEA $=.081$; Father Grade $3 \chi^{2}=$ $0.7, p=.710$, and RMSEA $=.000$. However, all other permutations produced models that were either unidentified or had much higher $\chi^{2}$ and RMSEA values, indicating a worse fit. Further, in each model the first factor, which represented the stress composite, accounted for more than $50 \%$ of the variance, while additional factors accounted for $18 \%$ or less. For each model the first factor was composed of positive loadings on all variables ranging from 0.6 to 0.8 . The other factors generally had high positive loadings from only one variable followed by low $(0.02-0.2)$ and/or negative loadings from all other variables. Thus it seems likely that the first factor generated by the PCA represents a good single measure of multi-source psychosocial stress.
} 
The correlated Grade 7 and 9 scores (Internalizing, $r=.62, p<$ .001 ; Externalizing, $r=.78, p<.001$ ) were averaged.

Because substantial overlap of internalizing and externalizing symptoms was observed $(r=.49, p<.001)$, we constructed two independent scales: Adolescent Symptom Severity (average of the two standardized scores, reflecting score commonality) and Adolescent Symptom Directionality (half difference of the standardized scores, reflecting what differentiates the scores; positive scores indicate a preponderance of externalizing symptoms). Importantly, Severity and Directionality are statistically independent and can be analyzed without additional Type I error (Essex, Klein, Cho, \& Kraemer, 2003; Essex et al., 2006). The Severity score was log transformed to normalize the distribution. Directionality was normally distributed.

Adolescent deviant peers. At Grade 9 adolescents completed an adaptation of the Self-Report of Close Friends from the Seattle Social Development Project (O'Donnell, Hawkins, \& Abbott, 1995). Items were rated on a 4-point scale ranging from 1 (Not at all) to 4 (Very much). Coefficients $\alpha$ were .60 or higher for Friends' Substance Use (e.g., "Have these people tried beer, wine, or liquor when their parents didn't know about it?"), Friends' Conduct Problems (e.g., "Have these people done anything that could have gotten them in trouble with the police?"), and Deviance with Friends (e.g., "Have you ever stolen something together?"). Correlated scales (all $r \mathrm{~s}>.64, p s<.001$ ) were combined using PCA; the first component accounted for $78 \%$ of total variance. All scales loaded at $\geq 0.87$. Distribution of the Deviant Friends score was normalized through log transformation. At Grade 9 participants also reported the predominant sex and age of their peers ("Are your friends mostly girls, mostly boys, or about half girls and half boys?" and "Are your friends mostly older, mostly younger, or about the same age as you?").

Grade 9 alcohol use. Consistent with major studies (e.g., Johnston, O'Malley, Bachman, \& Schulenberg, 2006; Johnston et al., 2009; Wright, Sathe, \& Spagnola, 2007), adolescents reported the typical number of alcoholic drinks consumed per occasion in the past 30 days ("On the days you drink alcohol, about how many drinks do you have? By a drink, I mean a can of beer, a glass of wine, a wine cooler, or a shot of hard liquor."). Participants chose one of six responses, "Less than a drink," "1 drink," "2 drinks," "3 drinks," "5 drinks," or "I don't drink alcohol." Participants were also asked if they had ever had alcohol (lifetime abstinence). Participants who answered "no" to question 2 and "I don't drink alcohol" to question 1 were assigned a score of 0 . Teens' alcohol use score corresponded to the number of alcoholic drinks typically consumed per drinking occasion at Grade 9. This score was log transformed to normalize the distribution.

\section{Alcohol Use Outcome: Grade 10 Typical Number of Drinks}

In Grade 10, Typical Number of Alcoholic Drinks consumed per drinking occasion in the past 30 days was assessed in the same manner described for Grade 9. To allow for ease of interpretation, this score was not log transformed, but instead coded into six categories; 0 (I don't drink alcohol), 1 (Less than a drink), 2 (1 drink), 3 (2 drinks), 4 (3 drinks), and 6 (5 drinks).

\section{Data Analysis}

Descriptive statistics for risk factors and the outcome were compiled for the entire sample and separately for boys and girls. One-way ANOVA was used to check for sex differences in the outcome and predictors. Predictors were correlated with each other and the outcome. Ordinal logistic regression analysis, which is appropriate for non-normally distributed outcome variables, was used to test major models. An initial full-sample model included child sex, SES, the two temperament factors, the three early family context factors, the four proximal adolescent factors, and to detect possible individual-by-context interactions, all two-way individual-by-context interactions and three-way sex-bytemperament-by-context interactions (18 interaction terms). Because significant sex interactions emerged, separate models were used to predict Grade 10 Typical Number of Drinks for girls and boys.

To address potential over-fitting the sex-specific models, the variables entered and their order of entry was determined by theoretical expectations. Variables were entered in blocks by developmental period (i.e., early, proximal) rather than allowing the statistical algorithm to choose best fit stepwise. The early individual and context factors and all two-way individual-by-context interactions were entered in the first step; to examine possible mediation, proximal factors were entered one at a time into the second step. Finally, to assess combined effects, all variables were entered in a full model. When coefficients from a continuous model were needed to test mediation or slopes, the results of parallel multiple linear regressions were used. Importantly, because multiple regression analysis is robust even with skewed outcome variables (Allison, 1999), the results of the multiple regression and ordinal logistic models were almost identical (analyses not shown), with major findings robust to statistical method and only a few minor exceptions for coefficients "hovering" around the significance level.

\section{Results}

\section{Descriptive Statistics}

Means and standard deviations for risk factors and the outcome are presented for the full sample and separately for boys and girls (Table 1). Consistent with national rates (Johnston et al., 2009), $59 \%$ (215) of the 362 participants reported alcohol use at Grade 10. Fifty-two percent of Drinkers (111) were boys. Boys also drank more than girls $(F=5.76, d f(1,360) p=.017$ : boys $M=1.46$, $S D=1.82$; girls $M=1.04, S D=1.52)$. Drinkers reported a range of alcohol consumption: 82 (38\% of drinkers) consumed fewer than one drink, $28(13 \%)$ consumed one drink, $24(11 \%)$ consumed two drinks, 37 (17\%) consumed three drinks, and 44 (20\%) consumed five drinks on a typical occasion. When considering the percentage of teens who consumed five drinks within the entire sample (44/362) the percentage is $12 \%$, lower but comparable to rates reported by Monitoring the Future 2008 (Johnston et al., 2009) which found $16 \%$ of 10th graders consumed five or more drinks on one occasion in the past two weeks.

ANOVA were conducted to test for sex differences in potential risk factors. Significant differences emerged for Preschool Temperamental Disinhibition $(F=8.43, d f(1,360) p=.004)$, Ado- 
Table 1

Descriptive Statistics for Full Sample and Separately for Girls and Boys

\begin{tabular}{|c|c|c|c|}
\hline & $\begin{array}{l}\text { Overall } \\
M(S D)\end{array}$ & $\begin{array}{c}\text { Girls } \\
M(S D)\end{array}$ & $\begin{array}{c}\text { Boys } \\
M(S D)\end{array}$ \\
\hline \multicolumn{4}{|l|}{ Early factors } \\
\hline Family SES & $0.06(0.97)$ & $0.05(1.00)$ & $0.07(0.93)$ \\
\hline Preschool temperamental disinhibition & $4.97(0.60)$ & $4.88(0.59)$ & $5.06(0.60)$ \\
\hline Preschool temperamental negative affect & $0.01(0.93)$ & $0.05(0.89)$ & $-0.05(0.96)$ \\
\hline Childhood parental stress (infancy, preschool, Grade 3) & $1.02(0.04)$ & $1.01(0.04)$ & $1.02(0.04)$ \\
\hline Childhood parental alcohol use (preschool, Grade 3) & $0.54(0.31)$ & $0.55(0.31)$ & $0.53(0.32)$ \\
\hline Childhood authoritative parenting style (preschool, Grade 3) & $6.24(0.37)$ & $6.27(0.39)$ & $6.21(0.36)$ \\
\hline \multicolumn{4}{|l|}{ Proximal factors } \\
\hline Adolescent symptom severity (Grades 7 \& 9) & $1.00(0.03)$ & $1.00(0.03)$ & $1.00(0.03)$ \\
\hline Adolescent symptom directionality (Grades 7 \& 9) & $-0.01(0.47)$ & $-0.21(0.40)$ & $0.22(0.42)$ \\
\hline Adolescent deviant friends (Grade 9) & $1.00(0.41)$ & $0.99(0.04)$ & $1.01(0.04)$ \\
\hline Grade 9 alcohol use & $0.17(0.23)$ & $0.16(0.22)$ & $0.19(0.23)$ \\
\hline \multicolumn{4}{|l|}{ Outcome } \\
\hline Typical number of drinks (Grade 10) & $1.24(1.68)$ & $1.04(1.52)$ & $1.46(1.82)$ \\
\hline
\end{tabular}

lescent Symptom Directionality $(F=99.15, d f(1,360) p<.001)$, and Adolescent Deviant Friends $(F=9.91, d f(1,360) p=.002)$. Boys exhibited greater disinhibition, a preponderance of externalizing symptoms, and greater association with deviant friends than girls.

No significant differences in Age of Friends by Sex emerged; $92 \%$ (159) of boys and $87 \%$ (166) of girls reported mostly same age friends. Roughly half (boys, $n=87,51 \%$; girls, $n=88,46 \%$ ) reported equal numbers of male and female friends, and half (girls, $n=97,51 \%$; boys, $n=73,42 \%$ ) mostly same-sex friends. Despite previous studies indicating the importance of peers' age and sex, too few participants had such friends to include these variables in analyses.

\section{Bivariate Associations of Putative Risk Factors and Outcomes}

Table 2 presents correlations of the early and adolescent predictors and the outcome for all participants and separately by sex. In the full sample, SES was significantly negatively correlated, and Preschool Temperamental Disinhibition significantly positively correlated with Grade 10 Typical Number of Drinks. Preschool Disinhibition and Negative Affect and Childhood Parental Stress were significantly correlated with greater Adolescent Mental Health Symptom Severity. Among the adolescent factors, Symptom Severity and Directionality, Deviant Friends, and Grade 9 Alcohol Use were strongly intercorrelated and all were positively associated with Grade 10 Typical Number of Drinks.

\section{Predictive Models}

The initial ordinal logistic model was run to identify and formally test sex differences in emergent interactions. This model was significant $\left(\chi^{2}=282.73, p<.001\right.$; Nagelkerke $\left.R^{2}=0.57\right)$ (Table 3). With all variables entered, one early factor was significant: higher levels of Childhood Authoritative Parenting Style predicted greater Grade 10 Typical Number of Drinks (before the inclusion of the proximal adolescent factors, which acted as mediators, a significant negative effect was also found for Family SES and a significant positive effect for Childhood Parental Al- cohol Use; analyses not shown). The interaction of Temperamental Disinhibition-by-Parental Alcohol Use was also significant. As expected, all proximal adolescent factors were significant: higher levels of Symptom Severity, Symptom Directionality (i.e., a preponderance of externalizing symptoms), Deviant Friends, and Grade 9 Alcohol Use predicted greater Grade 10 Typical Number of Drinks. Most importantly, three significant sex interactions emerged: Child Sex-by-Preschool Temperamental Negative Affect, Child Sex-by-Childhood Parental Alcohol Use, and Child Sex-by-Preschool Temperamental Disinhibition-by-Childhood Parental Stress. Thus, further analyses were conducted separately for girls and boys.

The results for girls (Table 4) showed that the early-factors-only model (Model 1) was significant $\left(\chi^{2}=35.87, p<.001\right.$; Nagelkerke $R^{2}=0.18$ ) and included two significant main effects and two significant interactions. Girls from lower SES families and those exposed to higher levels of parental alcohol use showed higher Grade 10 alcohol use. The results of Models 2-4 indicate Family SES was reduced to non-significance after the addition of any adolescent factor; Childhood Parental Alcohol Use was reduced to non-significance after the addition of Adolescent Deviant Friends. The two interaction terms-Temperamental Disinhibition-byParental Stress and Temperamental Disinhibition-by-Parental Alcohol Use-remained significant, and there was a significant sex difference only for Temperamental Disinhibition $\times$ Parental Stress (see corresponding three-way sex interactions in Table 3 ). With all variables included, the model was significant $\left(\chi^{2}=157.10, p<.001\right.$; Nagelkerke $R^{2}=0.60$ ).

Sobel's tests, based on values from parallel multiple linear regressions (analyses not shown), were used to test the mediating effects of proximal factors on the associations of Family SES and Childhood Parental Alcohol Use with Grade 10 Typical Number of Drinks. Three paths were tested. Family SES was significantly mediated by Adolescent Symptom Severity (Sobel Statistic = -2.82, $p=.005$ ) and Adolescent Deviant Friends (Sobel Statistic $=-3.99, p<.001$ ), and marginally mediated by Adolescent Symptom Directionality (Sobel Statistic $=-1.86, p=.063$ ). One path starting with Childhood Parental Alcohol Use was tested, 
Table 2

Nonparametric Correlations for Putative Risk Factors and Outcome (Full Sample/Girls/Boys)

\begin{tabular}{|c|c|c|c|c|c|c|c|c|c|c|}
\hline & 1 & 2 & 3 & 4 & 5 & 6 & 7 & 8 & 9 & 10 \\
\hline \multicolumn{11}{|c|}{ Early factors } \\
\hline 1. Family SES & - & & & & & & & & & \\
\hline \multirow[t]{2}{*}{ 2. Preschool temperamental disinhibition } & -.071 & & & & & & & & & \\
\hline & $\begin{array}{l}-.112 \\
-.025\end{array}$ & - & & & & & & & & \\
\hline \multirow[t]{3}{*}{ 3. Preschool temperamental negative affect } & -.041 & $.395^{* * * *}$ & & & & & & & & \\
\hline & -.004 & $.387^{* * * * *}$ & - & & & & & & & \\
\hline & -.087 & $.426^{* * * *}$ & & & & & & & & \\
\hline \multirow{3}{*}{$\begin{array}{l}\text { 4. Childhood parental stress (infancy, } \\
\text { preschool, Grade 3) }\end{array}$} & $-.154^{* * *}$ & $.187^{* * * *}$ & $.277^{* * * * *}$ & & & & & & & \\
\hline & -.082 & .131 & $.263^{* * * *}$ & - & & & & & & \\
\hline & $-.239^{* * *}$ & $.229^{* *}$ & $.305^{* * * *}$ & & & & & & & \\
\hline \multirow{3}{*}{$\begin{array}{l}\text { 5. Childhood parental alcohol } \\
\text { use (preschool, Grade 3) }\end{array}$} & .079 & -.038 & .006 & .062 & & & & & & \\
\hline & .111 & -.066 & -.107 & .118 & - & & & & & \\
\hline & .038 & .008 & .119 & .001 & & & & & & \\
\hline \multirow{3}{*}{$\begin{array}{l}\text { 6. Childhood authoritative parenting style } \\
\text { (preschool, Grade 3) }\end{array}$} & $.114^{*}$ & .001 & -.102 & $-.163^{* *}$ & $.120^{*}$ & & & & & \\
\hline & .101 & .007 & $-.184^{*}$ & $-.166^{*}$ & .053 & - & & & & \\
\hline & .118 & .011 & -.019 & $-.157^{*}$ & $.187^{*}$ & & & & & \\
\hline \multicolumn{11}{|c|}{ Proximal factors } \\
\hline \multirow{3}{*}{$\begin{array}{l}\text { 7. Adolescent symptom severity (Grades } 7 \\
\text { \& 9) }\end{array}$} & $-.308^{* * *}$ & $.249^{* * * *}$ & $.260^{* * * *}$ & $.357^{* * * *}$ & .067 & $-.171^{* *}$ & & & & \\
\hline & $-.289^{\text {**** }}$ & $.206^{* *}$ & $.189^{* * *}$ & $.347^{* * * * *}$ & .006 & $-.144^{*}$ & - & & & \\
\hline & $-.346^{* * *}$ & $.273^{* * *}$ & $346^{* * *}$ & $.368^{* * * *}$ & .143 & $-.193^{*}$ & & & & \\
\hline \multirow{3}{*}{$\begin{array}{l}\text { 8. Adolescent symptom } \\
\text { directionality (Grades } 7 \text { \& 9) }\end{array}$} & -.060 & $.171^{* *}$ & -.078 & -.062 & -.015 & -.029 & .012 & & & \\
\hline & -.141 & .114 & -.014 & $-.174 *$ & -.087 & .108 & $-.265^{* * *}$ & - & & \\
\hline & -.034 & .141 & -.072 & .033 & .121 & -.120 & $.267^{* * * * *}$ & & & \\
\hline \multirow[t]{3}{*}{ 9. Adolescent deviant friends (Grade 9) } & $-.277^{* * * *}$ & .101 & .007 & .018 & $.105^{*}$ & -.048 & $.369^{* * * *}$ & $.306^{* * * *}$ & & \\
\hline & $-.363^{* * * *}$ & .140 & .079 & -.031 & .127 & .017 & $.327^{* * * * *}$ & $.227^{* * *}$ & - & \\
\hline & $-.186^{*}$ & -.004 & -.048 & .071 & .109 & -.102 & $.402^{* * * *}$ & $.345^{\text {**** }}$ & & \\
\hline \multirow[t]{3}{*}{ 10. Grade 9 alcohol use } & $-.204^{* * * *}$ & .090 & -.033 & .034 & .102 & -.072 & $.265^{* * * *}$ & $.284^{* * * *}$ & $.658^{* * * *}$ & \\
\hline & $.282^{* * * *}$ & .084 & -.003 & .019 & $.145^{*}$ & -.028 & $.223^{* *}$ & $.221^{* * *}$ & $.674^{* * * * *}$ & - \\
\hline & -.115 & .072 & -.055 & .051 & .056 & -.120 & $.306^{* * *}$ & $.397^{* * * *}$ & $.645^{* * * *}$ & \\
\hline \multicolumn{11}{|c|}{ Outcome } \\
\hline \multirow[t]{3}{*}{ 11. Typical number of drinks (Grade 10) } & $-.168^{* *}$ & $.148^{* *}$ & .054 & .005 & .082 & .026 & $.305^{* * *}$ & $.319^{* * * *}$ & $.620^{* * * * *}$ & $.682^{* * * *}$ \\
\hline & $-.235^{* * *}$ & .132 & .036 & .017 & .130 & .038 & $.305^{* * * *}$ & $.242^{* * *}$ & $.677^{* * * * *}$ & $.696^{\text {***** }}$ \\
\hline & -.102 & .119 & .088 & -.012 & .039 & .023 & $.298^{* * * *}$ & $.367^{* * * *}$ & $.556^{* * * *}$ & $.669^{* * * *}$ \\
\hline
\end{tabular}

Note. All variables were centered on the mean before analyses.

${ }^{*} p<.05 .{ }^{* *} p<.01 .^{* * * *} p<.001$.

showing marginal mediation by Adolescent Deviant Friends (Sobel Statistic $=1.65, p=.099$ ).

To further investigate the two significant interactions, tests of simple slopes (Aiken \& West, 1991), based on values from the parallel multiple linear regressions, were conducted. Results for the Preschool Temperamental Disinhibition-by-Childhood Parental Stress interaction indicated that girls with high disinhibition drank more when exposed to high parental stress $(B=8.55, \beta=$ $0.21, t=2.69, p=.008)$. In contrast, girls with low disinhibition exhibited similar levels of alcohol consumption regardless of stress exposure $(B=-4.39, \beta=-0.11, t=-1.13, p=.259)$. The second interaction, Preschool Temperamental Disinhibition-byChildhood Parental Alcohol Use, did not produce significant slopes tests (high Preschool Disinhibition, $B=-.03, \beta=-0.01$, $t=-0.08, p=.934$; low Preschool Disinhibition, $B=.67, \beta=$ $0.14, t=1.76, p=.080)$.

The same procedures were followed for boys (Table 5). The early-factors-only model (Model 1) was not significant $\left(\chi^{2}=\right.$ $10.18, p=.600$, Nagelkerke $R^{2}=0.06$ ), and thus mediation effects were not tested (Models 2-4 are shown to be consistent with girls' models). The boys' full model was significant $\left(\chi^{2}=\right.$ 127.08, $p<.001$; Nagelkerke $\left.R^{2}=0.55\right)$ and included three significant main effects for Preschool Temperamental Negative Affect, Childhood Parental Stress, and Childhood Authoritative Parenting. That these early factors only emerge upon the addition of Grade 9 Alcohol Use indicates possible suppressor effects. Thus it is possible that within the context of high parental stress and authoritative parenting, boys with greater negative affect who were already using alcohol at Grade 9 had greater Grade 10 alcohol use. There was no sex difference in the effects of authoritative parenting or parental stress; however, a significant sex difference emerged for negative affect (see two-way sex interactions; Table 3).

\section{Discussion}

Because paths to alcohol use are multiple and multiply determined, this study sought to clarify the influence of several childhood and adolescent factors by investigating early individual-bycontext interactions, potential adolescent mediators, and the 
Table 3

Ordinal Logistic Regression Models Predicting Grade 10 Typical Number of Drinks for Full Sample

\begin{tabular}{|c|c|c|c|c|}
\hline & Estimate & $S E$ & Wald statistic & $p$ \\
\hline \multicolumn{5}{|l|}{ Early factors } \\
\hline Child sex $(-0.5=$ male $;+0.5=$ female $)$ & -0.185 & 0.262 & 0.500 & .480 \\
\hline Family SES & 0.052 & 0.129 & 0.161 & .688 \\
\hline Preschool temperamental disinhibition & 0.044 & 0.212 & 0.043 & .836 \\
\hline Preschool temperamental negative affect & 0.214 & 0.136 & 2.462 & .117 \\
\hline Childhood parental stress & -4.999 & 3.540 & 1.994 & .158 \\
\hline Childhood parental alcohol use & -0.178 & 0.377 & 0.223 & .637 \\
\hline Childhood authoritative parenting style & 1.106 & 0.332 & 11.112 & .001 \\
\hline Temperamental disinhibition $\times$ parental stress & 4.443 & 6.248 & 0.506 & .477 \\
\hline Temperamental disinhibition $\times$ authoritative parenting & -0.265 & 0.591 & 0.201 & .654 \\
\hline Temperamental disinhibition $\times$ parental alcohol use & -1.436 & 0.703 & 4.176 & .041 \\
\hline Temperamental negative affect $\times$ parental stress & 4.735 & 3.486 & 1.845 & .174 \\
\hline Temperamental negative affect $\times$ authoritative parenting & -0.071 & 0.379 & 0.036 & .850 \\
\hline Temperamental negative affect $\times$ parental alcohol use & -0.175 & 0.449 & 0.152 & .697 \\
\hline Child sex $\times$ family SES & 0.372 & 0.248 & 2.244 & .134 \\
\hline Child sex $\times$ temperamental disinhibition & 0.488 & 0.420 & 1.352 & .245 \\
\hline Child sex $\times$ temperamental negative affect & -0.592 & 0.273 & 4.704 & .030 \\
\hline Child sex $\times$ parental stress & 12.912 & 6.841 & 3.562 & .059 \\
\hline Child sex $\times$ authoritative parenting & -1.024 & 0.654 & 2.455 & .117 \\
\hline Child sex $\times$ parental alcohol use & 1.662 & 0.754 & 4.852 & .028 \\
\hline Child sex $\times$ temperamental disinhibition $\times$ parental stress & 34.064 & 12.538 & 7.381 & .007 \\
\hline Child sex $\times$ temperamental disinhibition $\times$ authoritative parenting & 1.867 & 1.185 & 2.484 & .115 \\
\hline Child se $\times$ temperamental disinhibition $\times$ parental alcohol use & -1.502 & 1.404 & 1.144 & .285 \\
\hline Child sex $\times$ temperamental negative affect $\times$ parental stress & -10.815 & 6.952 & 2.420 & .120 \\
\hline Child sex $\times$ temperamental negative affect $\times$ authoritative parenting & -0.349 & 0.753 & 0.215 & .643 \\
\hline Child sex $\times$ temperamental negative affect $\times$ parental alcohol use & -0.569 & 0.904 & 0.397 & .529 \\
\hline \multicolumn{5}{|l|}{ Proximal factors } \\
\hline Adolescent symptom severity & 11.321 & 3.931 & 8.293 & .004 \\
\hline Adolescent symptom directionality & 1.041 & 0.286 & 13.234 & $<.001$ \\
\hline Adolescent deviant friends & 12.792 & 4.096 & 9.752 & .002 \\
\hline Grade 9 alcohol use & 6.100 & 0.743 & 67.419 & $<.001$ \\
\hline
\end{tabular}

Note. Only significant interaction terms are presented. Model significant at $p<.001$, Nagelkerke $R^{2}=0.57$.

influence of sex using a prospective community sample. Consistent with past work adolescent deviant peers, externalizing symptoms, and past drinking predicted greater alcohol use (Alati et al., 2005; Dubow, Boxer, \& Huesmann, 2008; Kuntsche \& Jordan, 2006; Pitkanen et al., 2008). As has past work (Hayatbakhsh et al., 2008; Trim \& Chassin, 2008), the present findings suggest greater alcohol use is also predicted by childhood factors, including lower family SES and greater exposure to parental alcohol use. Importantly, the current study offers two significant extensions: (1) sex differences were observed in the contributions made by distal risk factors; and (2) the effects of early child and contextual factors were most evident in interaction with each other.

The initial model revealed a significant negative effect for family SES and significant positive effects for parental alcohol use and authoritative parenting style. While there were no significant sex differences, the influence of SES was best shown by the girls' models; a strong early influence differentially mediated by adolescent factors. Past research on SES and adolescent alcohol use has been equivocal (Tobler, Komro, \& Maldonado-Molina, 2009; Trim \& Chassin, 2008). High SES has been observed to predict more alcohol use (Trim \& Chassin, 2008) through greater access (Hearst et al., 2007; Tobler et al., 2009) and greater parental drinking (Chuang, Ennett, Bauman, \& Foshee, 2005) but to predict less use through stricter parenting (Spijkerman, van den Eijnden, \& Huiberts, 2008). Low SES predicts lax parenting (Guo et al.,
2001) and greater peer use (Chuang et al., 2005), especially among teens with alcoholic parents (Trim \& Chassin, 2008). The present results support the influence of SES through its effects on other factors.

Greater parental alcohol use was found to increase drinking for both boys and girls, but effects were strongest in girls (Table 3), consistent with suggestions that girls are more sensitive to early family context (Block \& Block, 1988; Pitkanen et al., 2008). The hypothesis that parental alcohol use would be mediated by the influence of deviant peers was only marginally supported, and then only for girls. While familial alcohol use and social behaviors likely interact with contextual demands to influence peer selection, peer group qualities are influenced by a range of non-familial variables, which may account for the observed weak or incomplete mediation.

In contrast to adolescent studies (Galaif et al., 2001; Johnson \& Johnson, 2001; van der Vorst et al., 2006), childhood authoritative parenting predicted greater alcohol consumption, even after adolescent factors were included. This finding is counterintuitive and difficult to interpret. It may be that authoritative parenting is different for parents of children versus adolescents. The current definition of authoritative parenting may have allowed for additional experiences that facilitate alcohol use. Also, only one parenting factor was assessed, disallowing the comparison of differing 
Table 4

Ordinal Logistic Regression Models Predicting Grade 10 Typical Number of Drinks for Girls

\begin{tabular}{|c|c|c|c|c|c|c|c|c|c|c|}
\hline & \multicolumn{2}{|c|}{ Model $1^{\mathrm{a}}$} & \multicolumn{2}{|c|}{ Model $2^{\mathrm{b}}$} & \multicolumn{2}{|c|}{ Model $3^{\mathrm{c}}$} & \multicolumn{2}{|c|}{ Model $4^{\mathrm{d}}$} & \multicolumn{2}{|c|}{ Full model $^{\mathrm{e}}$} \\
\hline & $\begin{array}{l}\text { Estimate } \\
\qquad(S E)\end{array}$ & Wald & $\begin{array}{l}\text { Estimate } \\
\qquad(S E)\end{array}$ & Wald & $\begin{array}{l}\text { Estimate } \\
\qquad(S E)\end{array}$ & Wald & $\begin{array}{l}\text { Estimate } \\
\qquad(S E)\end{array}$ & Wald & $\begin{array}{l}\text { Estimate } \\
\qquad(S E)\end{array}$ & Wald \\
\hline \multicolumn{11}{|l|}{ Early factors } \\
\hline Family SES & $-0.39(0.15)$ & $6.80^{* *}$ & $-0.26(0.16)$ & 2.74 & $-0.30(0.15)$ & 3.72 & $0.15(0.17)$ & 0.78 & $0.31(0.18)$ & 2.94 \\
\hline $\begin{array}{l}\text { Preschool temperamental } \\
\text { disinhibition }\end{array}$ & $0.52(0.28)$ & 3.56 & $0.39(0.28)$ & 1.89 & $0.53(0.29)$ & 3.39 & $0.39(0.30)$ & 1.69 & $0.29(0.31)$ & 0.87 \\
\hline $\begin{array}{l}\text { Preschool temperamental } \\
\text { negative affect }\end{array}$ & $-0.07(0.19)$ & 012 & $-0.11(0.19)$ & 0.31 & $-0.06(0.19)$ & 0.09 & $-0.14(0.20)$ & 0.50 & $-0.10(0.20)$ & 0.25 \\
\hline Childhood parental stress & $-0.25(4.05)$ & 0.00 & $-3.18(4.23)$ & 0.57 & $2.23(4.12)$ & 0.29 & $1.82(4.30)$ & 0.18 & $1.89(4.53)$ & 0.17 \\
\hline $\begin{array}{l}\text { Childhood parental } \\
\text { alcohol use }\end{array}$ & $1.29(0.49)$ & $6.85^{* *}$ & $1.31(0.50)$ & $6.93^{* *}$ & $1.44(0.51)$ & $8.00^{* *}$ & $0.87(0.53)$ & 2.75 & $0.77(0.56)$ & 1.90 \\
\hline $\begin{array}{l}\text { Childhood authoritative } \\
\text { parenting style }\end{array}$ & $0.21(0.39)$ & 0.30 & $0.33(0.39)$ & 0.70 & $0.16(0.39)$ & 0.15 & $0.28(0.41)$ & 0.46 & $0.58(0.44)$ & 1.77 \\
\hline $\begin{array}{l}\text { Temperamental } \\
\text { disinhibition } \times \\
\text { parental stress }\end{array}$ & $19.02(7.85)$ & $5.87^{*}$ & $19.65(7.86)$ & $6.25^{*}$ & $16.18(7.99)$ & $4.10^{*}$ & $25.45(8.38)$ & $9.23^{* *}$ & $22.33(8.51)$ & $6.88^{* *}$ \\
\hline $\begin{array}{l}\text { Temperamental } \\
\text { disinhibition } \times \\
\text { parental alcohol use }\end{array}$ & $-2.51(0.93)$ & $7.26^{* *}$ & $-2.37(0.94)$ & $6.29^{*}$ & $-3.00(0.99)$ & $9.22^{* *}$ & $-2.19(1.01)$ & $4.73^{*}$ & $-2.37(1.09)$ & $4.75^{*}$ \\
\hline \multicolumn{11}{|l|}{ Proximal factors } \\
\hline $\begin{array}{l}\text { Adolescent symptom } \\
\text { severity } \\
\text { Adolescent symptom }\end{array}$ & - & - & $15.89(4.94)$ & $10.33^{* * * *}$ & - & - & - & - & $14.47(5.83)$ & $6.17^{*}$ \\
\hline $\begin{array}{l}\text { directionality } \\
\text { Adolescent deviant }\end{array}$ & - & - & - & - & $1.36(0.38)$ & $12.97^{* * * *}$ & - & - & $1.33(0.43)$ & $9.63^{* *}$ \\
\hline friends & - & - & - & - & - & - & $42.07(5.27)$ & $63.67^{* * * *}$ & $16.98(6.55)$ & $6.72^{* *}$ \\
\hline Grade 9 alcohol use & - & - & - & - & - & - & - & - & $5.93(1.08)$ & $\mathbf{3 0 . 3 8}^{\text {*****⿲二丨匕 }}$ \\
\hline
\end{tabular}

Note. Only significant interaction terms are presented.

${ }^{\mathrm{a}}$ Model significant at $p<.001$, Nagelkerke $R^{2}=0.18$. ${ }^{\mathrm{b}}$ Model significant at $p<.001$, Nagelkerke $R^{2}=0.23$. ${ }^{\mathrm{c}}$ Model significant at $p<.001$, Nagelkerke $R^{2}=0.24$. ${ }^{\mathrm{d}}$ Model significant at $p<.001$, Nagelkerke $R^{2}=0.48$. ${ }^{\text {e }}$ Model significant at $p<.001$, Nagelkerke $R^{2}=0.60$.

${ }^{*} p<.05 . \quad{ }^{* *} p<.01 .{ }^{* * * *} p<.001$.

styles or control of development differences. More study is needed.

Significant sex differences in the full model prompted the use of separate models for girls and boys. For girls, Grade 10 alcohol use was predicted not only by adolescent factors but also by temperament in interaction with the family context. Contrary to expectation, it was early disinhibition and not negative affect that interacted with high family stress to predict greater alcohol use among adolescent girls. It was hypothesized that the effects of early stress would be mediated by adolescent mental health. However, the stress-by-disinhibition interaction remained significant in the full model, suggesting early stress in combination with individual traits confers risk for heavier alcohol use not accounted for by adolescent constructs. Past research has implicated high concurrent life stress in problematic adolescent alcohol use (Aseltine \& Gore, 2000; Johnson \& Pandina, 1993), and greater exposure to early stress sensitizes physiological stress response and predicts mental health problems (Essex et al., 2002b). Together, these studies, including the present results, suggest that differences in temperamental sensitivity, physiological reactivity, and sex interact with the environment to drive differential vulnerability to alcohol use (Caspi et al., 2003; Covault et al., 2007; Kaufman et al., 2007).

Further support emerges from studies of non-human primates (rhesus macaques) that indicate individuals exposed to chronic developmental stress (peer-rearing) (Fahlke et al., 2000; Higley,
Hasert, Suomi, \& Linnoila, 1991) and those with greater infantile physiological reactivity (Fahlke et al., 2000), particularly chronically stressed females (Barr et al., 2004), freely consume greater and/or increasing amounts of alcohol as young adults. Similarly, in the present study, highly disinhibited girls who were also exposed to developmental stress exhibited greater adolescent alcohol consumption. To our knowledge this is the first time such effects have been observed in a prospective study of adolescent alcohol use. As does preclinical work, the current study suggests links between sex, temperament, and developmental stress and supports the need for additional investigation of individual-by-context and gene-byenvironment interactions that could potentially aid in the development of targeted prevention and treatment strategies.

The only main effect specific to boys was that of preschool negative affect. Consistent with past work (Caspi et al., 1996; Hawkins et al., 1999), boys with greater preschool negative affect reported greater adolescent alcohol use. Suppressor effects were indicated as preschool negative affect only emerged as significant within the context of greater Grade 9 alcohol use. It is interesting, however, that negative affect increased boys' risk but not girls', as theoretical work has supposed the opposite. The expected mediation of negative affect by adolescent mental health was not observed, possibly because of a lack of power, as sample size decreased when analyses were split by gender. Finally, exposure to early parental stress predicted less alcohol use in boys, although it 
Table 5

Ordinal Logistic Regression Models Predicting Grade 10 Typical Number of Drinks for Boys

\begin{tabular}{|c|c|c|c|c|c|c|c|c|c|c|}
\hline & \multicolumn{2}{|c|}{ Model $1^{\mathrm{a}}$} & \multicolumn{2}{|c|}{ Model $2^{\mathrm{b}}$} & \multicolumn{2}{|c|}{ Model $3^{\mathrm{c}}$} & \multicolumn{2}{|c|}{ Model $4^{\mathrm{d}}$} & \multicolumn{2}{|c|}{ Full model $^{\mathrm{e}}$} \\
\hline & Estimate $(S E)$ & Wald & Estimate $(S E)$ & Wald & Estimate $(S E)$ & Wald & Estimate $(S E)$ & Wald & Estimate $(S E)$ & Wald \\
\hline \multicolumn{11}{|l|}{ Early factors } \\
\hline Family SES & $-0.27(0.17)$ & 2.66 & $-0.09(0.17)$ & 0.25 & $-0.30(0.17)$ & 3.19 & $-0.12(0.18)$ & 0.44 & $-0.15(0.19)$ & 0.58 \\
\hline $\begin{array}{l}\text { Preschool temperamental } \\
\text { disinhibition }\end{array}$ & $0.18(0.27)$ & 0.45 & $0.06(0.27)$ & 0.05 & $-0.11(0.28)$ & 0.15 & $0.08(0.28)$ & 0.07 & $-0.16(0.30)$ & 0.30 \\
\hline $\begin{array}{l}\text { Preschool temperamental } \\
\text { negative affect }\end{array}$ & $0.12(0.17)$ & 0.53 & $0.04(0.17)$ & 0.06 & $0.30(0.18)$ & 2.94 & $0.34(0.18)$ & 3.63 & $0.49(0.19)$ & $6.78^{* *}$ \\
\hline $\begin{array}{l}\text { Childhood parental stress } \\
\text { Childhood parental }\end{array}$ & $-1.04(4.71)$ & 0.05 & $-6.14(4.97)$ & 1.52 & $-1.33(4.82)$ & 0.08 & $-4.51(4.96)$ & 0.82 & $-10.96(5.59)$ & $3.84^{*}$ \\
\hline $\begin{array}{l}\text { alcohol use } \\
\text { Childhood authoritative }\end{array}$ & $0.13(0.47)$ & 0.08 & $-0.21(0.48)$ & 0.19 & $-0.34(0.49)$ & 0.49 & $-0.31(0.49)$ & 0.40 & $-0.88(0.53)$ & 2.75 \\
\hline $\begin{array}{l}\text { parenting style } \\
\text { Temperamental }\end{array}$ & $0.58(0.44)$ & 1.77 & $0.86(0.46)$ & 3.54 & $1.07(0.46)$ & $5.53^{*}$ & $0.85(0.47)$ & 3.45 & $1.47(0.51)$ & $8.38^{* *}$ \\
\hline $\begin{array}{l}\text { disinhibition } \times \\
\text { authoritative parenting }\end{array}$ & $-1.76(0.84)$ & $4.44^{*}$ & $-1.64(0.86)$ & 3.67 & $-2.04(0.85)$ & $5.72^{*}$ & $-1.01(0.88)$ & 1.34 & $-1.05(0.95)$ & 1.21 \\
\hline \multicolumn{11}{|l|}{ Proximal factors } \\
\hline $\begin{array}{l}\text { Adolescent symptom } \\
\text { severity } \\
\text { Adolescent symptom }\end{array}$ & - & - & $19.55(5.16)$ & $14.37^{* * * *}$ & - & - & - & - & $9.36(5.64)$ & 2.75 \\
\hline $\begin{array}{c}\text { directionality } \\
\text { Adolescent deviant }\end{array}$ & - & - & - & - & $1.81(0.38)$ & $22.27^{\text {**** }}$ & - & - & $0.71(0.41)$ & 2.96 \\
\hline friends & - & - & - & - & - & - & $30.21(4.20)$ & $51.63^{* * * *}$ & $9.30(5.31)$ & 3.07 \\
\hline Grade 9 alcohol use & - & - & - & - & - & - & - & - & $6.61(1.08)$ & $37.42^{* * * *}$ \\
\hline
\end{tabular}

Note. Only significant interaction terms are presented.

${ }^{\mathrm{a}}$ Model not significant, $p=.600$, Nagelkerke $R^{2}=0.06 .{ }^{\mathrm{b}}$ Model significant at $p=.022$, Nagelkerke $R^{2}=0.14$. ${ }^{\mathrm{c}}$ Model significant at $p<.001$, Nagelkerke $R^{2}=0.19$. ${ }^{\mathrm{d}}$ Model significant at $p<.001$, Nagelkerke $R^{2}=0.37$. ${ }^{\text {e }}$ Model significant at $p<.001$, Nagelkerke $R^{2}=0.55$.

${ }^{*} p<.05$. *** $p<.01$. **** $p<.001$.

is less likely a significant sex difference as it was not significant in the mixed-gender model (Table 3) nor in the girls'. As little research has been conducted on sex differences of early stress exposure and teen drinking, specific conclusions are premature.

Although the current findings replicate past work with adolescents, their importance lies not in this replication but rather in the linking of adolescent alcohol use to the interaction of early child proclivities and environmental context. Preschool temperamental disinhibition and negative affect were both significantly associated with the severity of adolescent mental health symptoms and support the proposal that later mental health may mediate the effects of early temperament. For girls, there were indications the disinhibition-by-stress interaction was partially mediated by externalizing symptoms and the effects of parental alcohol mediated use by the influence of deviant peers. However, formal tests were not significant, thus this study only weakly supports epigenetic hypotheses that early factors are mediated by adolescent constructs.

Studies of temperament in late childhood have demonstrated mediation by adolescent constructs, particularly with regard to self-control (Wills \& Stoolmiller, 2002). To our knowledge these relationships have not been explored using early measures of temperament and family context or adolescent constructs other than behavioral control. In the present study two major early temperamental domains suggested by the literature, negative affect and disinhibition, were not strongly related to well-supported adolescent risk factors for alcohol use and mediation as predicted by epigenetic theory was not strongly observed. Alternate childhood and/or adolescent factors may have yielded different results.
Intermediaries such as changing parent-child relationships or concurrent life stressors are likely contributors to adolescent risk for alcohol use and represent an area ripe for developmental investigation.

Although preliminary in nature, these finding do have implications for identifying high-risk groups and for timing intervention efforts. Sex-specific models suggest girls' risk for alcohol use is a joint consequence of the independent effects of childhood individual and contextual risk and adolescent social risk. Because of this, it may be possible to predict girls' risk before adolescence based on level of temperamental disinhibition and psychosocial stress exposure or at adolescence based on current friendships. It is likely relationships with deviant peers trigger and maintain social behaviors associated with early disinhibition and thus exacerbate risk. For boys' identifying negative affect and authoritative parenting may be important as these joint effects may indicate some mismatch of temperament and parenting behavior. Unrelated work suggests early negative affect interacts with parenting to influence behavioral outcomes (Cook, Schoppe-Sullivan, Buckley, \& Davis, 2009; Lagace-Seguin \& d'Entremont, 2006), and similar effects for alcohol use are possible. The effects of early factors for boys must be interpreted cautiously, however, as these emerged only in the context of ongoing adolescent alcohol use. Thus, different prevention pathways and intervention timelines are likely for girls and boys. For girls it may prove beneficial to begin efforts supporting self-regulation and parental consistency before adolescence, as early risk factors appear to have consequences independent of adolescent factors, especially for disinhibited girls from 
highly stressed or chaotic families. Boys with high negative affect may benefit from efforts aimed at emotion regulation and positive coping across development. Thus the current findings may inform a range of interventions to minimize alcohol problems and target specific areas of risk.

\section{Limitations}

Although intriguing, these findings must be considered in light of a number of limitations. First, the limited mediation of early individual-context interactions by adolescent factors and the lack of direct effects of early factors for boys may be more reflective of the factors chosen for inclusion in the tested models rather than any theoretical deficiencies. Clearly other family, neighborhood, and community context factors influence alcohol use, and alternate combinations of distal and proximal characteristics would likely yield different relationships. The lack of strong effects from early factors may stem from how the current and previous studies have differentially defined early characteristics, from the more or less unique combinations of distal and proximal predictors used in models, whether sex was considered, or whether samples were only boys or only girls. Further, of studies that have found strong early effects (Alati et al., 2005; Caspi et al., 1997; Englund et al., 2008; Guo et al., 2001; Niemela et al., 2006), most have not investigated the influence of individual-context interactions. Moreover, past studies have predicted adult not adolescent alcohol use (Dubow, Boxer, \& Huesmann, 2008; Englund et al., 2008) and predicted to different outcomes, including initiation of alcohol use (Hayatbakhsh et al., 2008; Williams et al., 2007), clinical alcohol problems (Alati et al., 2005; Caspi et al., 1996), or an aggregate of risky health behaviors (Caspi et al., 1997), but not, as in the current study, to the number of drinks consumed per drinking occasion. Because longitudinal studies extending from infancy to adolescence are still relatively infrequent, such heterogeneity of method and results is not unexpected and future replications should address these concerns.

Second, generalizability may be limited by the increased homogeneity produced by the inclusion criteria during subject recruitment. Third, the measure of parental alcohol use was limited as only mother's reports of parental use were available. The addition of fathers' report of their own behavior may have altered results. Fourth, authoritative parenting and autonomy granting were measured at Grade 3 using items that differed from those typically used with adolescents. Additionally, there is some debate as to whether anger, as an affective state, is more similar or different than other negative states such as sadness and fear (Carver \& Harmon-Jones, 2009; Watson, 2009). Further, whether childhood expressions of anger are comparable to adolescent hostility in influence on alcohol use is not known. Thus authoritative parenting and negative affect as defined in the present study may be by definition different from constructs used in other work. Fifth, the current study lacked an explicit measure of the frequency of adolescent binge drinking; a more precise measure may have produced different results. Sixth, this study did not examine genetic contributions or physiological measures of stress. The future collection of such data from a wide cross-section of individuals is crucial to fully understanding the role of individual-context interactions in alcohol use. Finally, although significant sex differences were observed, replication and extension are needed, including the use of alternate statistical approaches that explicitly compare predictive models.

\section{Strengths and Future Directions}

Importantly, the present study extends past research by highlighting the interaction of early risk factors and suggesting that common childhood experiences, such as family stress, likely produce different effects depending on sex and temperament. Work exploring such interactions is crucial to improving targeted prevention and treatment strategies and should focus more specifically on how sex and other individual-context interactions inform detection of at-risk individuals. Although data assessing alcohol use trajectories are not yet available for this sample, data collection continues and future work will focus on broad patterns of use and associated problems. Indeed, different findings may well emerge when predicting alcohol use at alternate ages. Despite its limitations, this study contributes to the growing body of developmental research aimed at explicating risk for adolescent alcohol use as well as to future efforts to translate such research to effective health policy.

\section{References}

Abidin, R. R. (1986). Parenting Stress Index (2nd ed.). Charlottesville, VA: Pediatric Psychology Press.

Aiken, L. S., \& West, S. G. (1991). Multiple regression: Testing and interpreting interactions. Thousand Oaks, CA: Sage Publications.

Alati, R., Najman, J. M., Kinner, S. A., Mamun, A. A., Williams, G. M., O'Callaghan, M., \& Bor, W. (2005). Early predictors of adult drinking: A birth cohort study. American Journal of Epidemiology, 162, 10981107.

Allison, P. D. (1999). Multiple regression: A primer. Thousand Oaks, CA: Pine Forge Press.

Ammon, E., Schafer, C., Hofmann, U., \& Klotz, U. (1996). Disposition and first-pass metabolism of ethanol in humans: Is it gastric or hepatic and does it depend on gender? Clinical Pharmacology and Therapeutics, 59, 503-513.

Aseltine, J. R. H., \& Gore, S. L. (2000). The variable effects of stress on alcohol use from adolescence to early adulthood. Substance Use and Misuse, 35(5), 643-668.

Babor, T. F., \& Winstanley, E. L. (2008). The world of drinking: National alcohol control experiences in 18 countries. Addiction, 103(5), 721-725.

Barnett, R. C., \& Marshall, N. L. (1989). Preliminary manual for the Role-Quality Scales. Wellesley College: Center for Research on Women.

Barr, C. S., Newman, T. K., Lindell, S., Shannon, C., Champoux, M., Lesch, K. P., . . . Higley, J. D. (2004). Interaction between serotonin transporter gene variation and rearing condition in alcohol preference and consumption in female primates. Archives of General Psychiatry, 61, 1146-1152.

Block, J., \& Block, J. H. (1988). Longitudinally foretelling drug usage in adolescence: Early childhood personality and environmental precursors. Child Development, 59, 336-355.

Block, J. H. (1965). The Child-Rearing Practices Report (CRPR): A set of $Q$ items for the description of parental socialization attitudes and values. Berkeley, CA: Institute of Human Development.

Boyce, W. T., Essex, M. J., Goldstein, L. H., Armstrong, J. M., Kraemer, H. C., \& Kupfer, D. J. (2002). The confluence of mental, physical, social, and academic difficulties in middle childhood. I: Exploring the "headwaters" of early life morbidities. Journal of the American Academy of Child and Adolescent Psychiatry, 41(5), 580-587.

Carver, C. S., \& Harmon-Jones, E. (2009). Anger and approach: Reply to 
Watson (2009) and to Tomarken and Zald (2009). Psychological Bulletin, 135(2), 215-217.

Caspi, A., Begg, D., Dickson, N., Harrington, H., Langley, J., Moffitt, T. E., \& Silva, P. A. (1997). Personality differences predict health-risk behaviors in young adulthood: Evidence from a longitudinal study. Journal of Personality and Social Psychology, 75(5), 1052-1063.

Caspi, A., Henry, B., McGee, R. O., Moffitt, T. E., \& Silva, P. A. (1995). Temperamental origins of child and adolescent behavior problems: From age three to age fifteen. Child Development, 66, 55-68.

Caspi, A., Moffitt, T. E., Newman, D. L., \& Silva, P. A. (1996). Behavioral observations at age 3 years predict adult psychiatric disorders: Longitudinal evidence from a birth cohort. Archives of General Psychiatry, 53, 1033-1039.

Caspi, A., Sugden, K., Moffitt, T. E., Taylor, A., Craig, I. W., Harrington, H., . . Poulton, R. (2003). Influence of life stress on depression: Moderation by a polymorphism in the 5-HTT gene. Science, 18(301), 386389.

Catalano, R. F., Kosterman, R., Hawkins, J. D., \& Newcomb, M. D. (1996). Modeling the etiology of adolescent substance use: A test of the social development model. Journal of Drug Issues, 26(2), 429-455.

Chuang, Y. C., Ennett, S. T., Bauman, K. E., \& Foshee, V. A. (2005). Neighborhood influences on adolescent cigarette and alcohol use: Mediating effects through parent and peer behaviors. Journal of Health and Social Behavior, 46(2), 187-204.

Cook, J. C., Schoppe-Sullivan, S. J., Buckley, C. K., \& Davis, E. F. (2009). Are some children harder to coparent than others? Children's negative emotionality and coparenting relationship quality. Journal of Family Psychology, 23(4), 606-610.

Costa, F. M., Jessor, R., \& Turbin, M. S. (1999). Transition into adolescent problem drinking: The role of psychosocial risk and protective factors. Journal of Studies on Alcohol, 60, 480-490.

Covault, J., Tennen, H., Armeli, S., Conner, T. S., Herman, A. I., Cillessen, A. H. N., \& Kranzler, H. R. (2007). Interactive effects of the serotonin transporter 5-HTTLPR polymorphism and stressful life events on college student drinking and drug use. Biological Psychiatry, 61(5), 609616.

De Bellis, M. D. (2002). Developmental traumatology: A contributory mechanism for alcohol and substance use disorders. Psychoneuroendocrinology, 27, 155-170.

Dick, D. M., Pagan, J. L., Holliday, C., Viken, R., Pulkkinen, L., Kaprio, J., \& Rose, R. J. (2007). Gender differences in friends' influences on adolescent drinking: A genetic epidemiological study. Alcoholism: Clinical and Experimental Research, 31(12), 2012-2019.

Dubow, E. F., Boxer, P., \& Huesmann, L. R. (2008). Childhood and adolescent predictors of early and middle adulthood alcohol use and problem drinking: The Columbia County Longitudinal Study. Addiction, 103(Suppl. 1), 36-47.

Duncan, S. C., Duncan, T. E., Biglan, A., \& Ary, D. V. (1998). Contributions of the social context to the development of adolescent substance use: A multivariate latent growth modeling approach. Drug and Alcohol Dependence, 50, 57-71.

Dunteman, G. H. (1989). Principal components analysis (Sage University Paper series on Quantitative Applications in the Social Sciences Series, No. 69). Newberry Park, CA: Sage Publications.

Ellis, B. J., Essex, M. J., \& Boyce, W. T. (2005). Biological sensitivity to context: II. Empirical explorations of an evolutionary-developmental theory. Development and Psychopathology, 17, 303-328.

Englund, M. M., Egeland, B., Oliva, E. M., \& Collins, W. A. (2008). Childhood and adolescent predictors of heavy drinking and alcohol use disorders in early adulthood: A longitudinal developmental analysis. Addiction, 103(Suppl. 1), 23-35.

Ennett, S. T., Foshee, V. A., Bauman, K. E., Hussong, A., Cai, L., Reyes, H. L., . . Durant, R. (2008). The social ecology of adolescent alcohol misuse. Child Development, 79(6), 1777-1791.
Essex, M. J., Boyce, W. T., Goldstein, L. H., Armstrong, J. M., Kraemer, H. C., \& Kupfer, D. J. (2002a). The confluence of mental, physical, social, and academic difficulties in middle childhood: II. Developing the MacArthur Health and Behavior Questionnaire. Journal of the American Academy of Child and Adolescent Psychiatry, 41(5), 588-603.

Essex, M. J., Klein, M. H., Cho, E., \& Kalin, N. H. (2002b). Maternal stress beginning in infancy may sensitize children to later stress exposure: Effects on cortisol and behavior. Biological Psychiatry, 52(8), 776-784.

Essex, M. J., Klein, M. H., Cho, E., \& Kraemer, H. C. (2003). Exposure to maternal depression and marital conflict: Gender differences in children's later mental health symptoms. Journal of the American Academy of Child and Adolescent Psychiatry, 42(6), 728-737.

Essex, M. J., Klein, M. H., Slattery, M. J., Goldsmith, H. H., \& Kalin, N. H. (2010). Early risk factors and developmental pathways to chronic high inhibition and social anxiety disorder in adolescence. American Journal of Psychiatry, 167(1), 40-46.

Essex, M. J., Kraemer, H. C., Armstrong, J. M., Boyce, W. T., Goldsmith, H. H., Klein, M. H., Kupfer, D. J. (2006). Exploring risk factors for the emergence of children's mental health problems. Archives of General Psychiatry, 63, 1246-1256.

Fahlke, C., Lorenze, J. G., Long, J., Champoux, M., Suomi, S. J., \& Higley, J. D. (2000). Rearing experiences and stress induced plasma cortisol as early risk factors for excessive alcohol consumption in nonhuman primates. Alcoholism: Clinical and Experimental Research, 24(5), 644650.

Fergusson, D. M., Horwood, L. J., \& Lynskey, M. T. (1995). The prevalence and risk factors associated with abusive or hazardous alcohol consumption in 16-year-olds. Addiction, 90, 935-946.

Frezza, M., di Padova, C., Pozzato, G., Terpin, M., Baraona, E., \& Lieber, C. S. (1990). High blood alcohol levels in women: The role of decreased gastric alcohol dehydrogenase activity and first-pass metabolism. New England Journal of Medicine, 322(2), 95-99.

Frick, P. J., \& Morris, A. S. (2004). Temperament and developmental pathways to conduct problems. Journal of Clinical Child and Adolescent Psychology, 33, 54-68.

Galaif, E. R., Stein, J. A., Newcomb, M. D., \& Bernstein, D. P. (2001) Gender differences in the prediction of problem alcohol use in adulthood: Exploring the influence of family factors and childhood maltreatment. Journal of Studies on Alcohol, 62, 486-493.

Gaughan, M. (2006). The gender structure of adolescent peer influence on drinking. Journal of Health and Social Behavior, 47, 47-61.

Grant, B., \& Dawson, D. (1997). Age of onset of alcohol use and its association with DSM-IV alcohol abuse and dependence: Results from the National Longitudinal Alcohol Epidemiologic Survey. Journal of Substance Abuse, 9, 103-110.

Guo, J., Hawkins, J. D., Hill, K. G., \& Abbott, R. D. (2001). Childhood and adolescent predictors of alcohol abuse and dependence in young adulthood. Journal of Studies on Alcohol, 62(6), 754-762.

Halberstadt, A. G. (1986). Family socialization of emotional expression and nonverbal communication styles and skills. Journal of Personality and Social Psychology, 51(4), 827-836.

Hamburger, M. E., Leeb, R. T., \& Swahn, M. H. (2008). Childhood maltreatment and early alcohol use among high-risk adolescents. Journal of Studies on Alcohol and Drugs, 69(2), 291-295.

Hammen, C., Brennan, P. A., \& Shih, J. (2004). Family discord and stress predictors of depression and other disorders in adolescent children of depressed and nondepressed women. Journal of the American Acadamy of Child \& Adolescent Psychiatry, 43(8), 994-1002

Hanson, M. D., \& Chen, E. (2007). Socioeconomic status and health behaviors in adolescence: A review of the literature. Journal of Behavioral Medicine, 30(3), 263-285.

Hawkins, J. D., Catalano, R., Kosterman, R., Abbott, R. D., \& Hill, K. G. (1999). Preventing adolescent health risk behaviors by strengthening 
protection during childhood. Archives of Pediatric and Adolescent Medicine, 153, 226-234.

Hawkins, J. D., Catalano, R. F., \& Miller, J. Y. (1992). Risk and protective factors for alcohol and other drug problems in adolescence and early adulthood: Implications for substance abuse prevention. Psychological Bulletin, 112, 64-105.

Hawkins, J. D., Graham, J. W., Maguin, E., Abbott, R. D., Hill, K. G., \& Catalano, R. (1997). Exploring the effects of age of alcohol use initiation and psychosocial risk factors on subsequent alcohol misuse. Journal of Studies on Alcohol, 58, 280-290.

Hayatbakhsh, M. R., Mamun, A. A., Najman, J. M., O’Callaghan, M. J., Bor, W., \& Alati, R. (2008). Early childhood predictors of early substance use and substance use disorders: Prospective study. Australian and New Zealand Journal of Psychiatry, 42(8), 720-731.

Hearst, M. O., Fulkerson, J. A., Maldonado-Molina, M. M., Perry, C. L., \& Komro, K. A. (2007). Who needs liquor stores when parents will do? The importance of social sources of alcohol among young urban teens. Preventive Medicine, 44(6), 471-476.

Higley, J. D., Hasert, M. R., Suomi, S. J., \& Linnoila, M. (1991). Nonhuman primate model of alcohol abuse: Effects of early experience, personality, and stress on alcohol consumption. Proceedings of the National Academy of Sciences of the United States of America, 88, 7261-7265.

Hussong, A., Curran, P. J., \& Chassin, L. (1998). Pathways of risk for accelerated heavy alcohol use among adolescent children of alcoholic parents. Journal of Abnormal Child Psychology, 26(6), 453-466.

Hyde, J. S., Klein, M. H., Essex, M. J., \& Clark, R. (1995). Maternity leave and women's mental health. Psychology of Women Quarterly, 19, 257285 .

Johnson, P. B., \& Johnson, H. L. (2001). Reaffirming the power of parental influence on adolescent smoking and drinking decisions. Adolescent and Family Health, 1(1), 37-43.

Johnson, V., \& Pandina, R. J. (1993). A longitudinal examination of the relationships among stress, coping strategies, and problems associated with alcohol use. Alcoholism: Clinical and Experimental Research, 17(3), 696-702.

Johnston, L. D., O’Malley, P. M., Bachman, J. G., \& Schulenberg, J. (2009). Monitoring the Future national results on adolescent drug use: Overview of key findings, 2008 (NIH Publication No. 09-7401): Bethesda, MD: National Institute on Drug Abuse

Johnston, L. D., O’Malley, P. M., Bachman, J. G., \& Schulenberg, J. (2006). Monitoring the Future national survey results on drug use: Overview of key findings 2005 (NIH Publication No. 06-5882): Bethesda, MD: National Institute of Drug Abuse.

Kandel, D. B., Johnson, J. G., Bird, H. R., Canino, G., Goodman, S. H., Lahey, B. B., . . . Schwab-Stone, M. (1997). Psychiatric disorders associated with substance use among children and adolescents: Findings from the Methods for the Epidemiology of Child and Adolescent Mental Disorders (MECA) Study. Journal of Abnormal Child Psychology, 25(2), 121-132

Kaplow, J. B., \& Widom, C. S. (2007). Age of onset of child maltreatment predicts long-term mental health outcomes. Journal of Abnormal Psychology, 116(1), 176-187.

Kaufman, J., Yang, B-Z., Douglas-Palumberi, H., Crouse-Artus, M., Lipschitz, D., Krystal, J. H., Gelernter, J. (2007). Genetic and environmental predictors of early alcohol use. Biological Psychiatry, 61(11), 12281234.

Keyes, K. M., Grant, B. F., \& Hasin, D. S. (2008). Evidence for a closing gender gap in alcohol use, abuse, and dependence in the United States population. Drug and Alcohol Dependence, 93(1-2):21-29.

Kirisci, L., Tarter, R. E., Mezzich, A. C., \& Vanyukov, M. (2007). Developmental trajectory classes in substance use disorder etiology. Psychology of Addictive Behaviors, 21(3), 287-296.

Kraemer, H. C., Measelle, J. R., Ablow, J. C., Essex, M. J., Boyce, W. T., \& Kupfer, D. J. (2003). A new approach to integrating data from multiple informants in psychiatric assessment and research: Mixing and matching contexts and perspectives. American Journal of Psychiatry, 160, 1566-1577.

Kuntsche, E., Gmel, G., Wicki, M., Rehm, J., \& Grichting, E. (2006). Disentangling gender and age effects on risky single occasion drinking during adolescence. European Journal of Public Health, 16(6), 670675 .

Kuntsche, E., \& Jordan, M. D. (2006). Adolescent alcohol and cannabis use in relation to peer and school factors: Results of multilevel analyses Drug and Alcohol Dependence, 84, 167-174.

Kuntsche, E., Knibbe, R., Gmel, G., \& Engels, R. (2006). Who drinks and why? A review of socio-demographic, personality, and contextual issues behind the drinking motives in young people. Addictive Behaviors, 31, 1844-1857.

Lagace-Seguin, D. G., \& d'Entremont, M.-R. L. (2006). The role of child negative affect in the relations between parenting styles and play. Early Child Development and Care, 176(5), 461-477.

Lande, R. G., Marin, B. A., Chang, A. S., \& Lande, G. R. (2007). Gender differences and alcohol use in the US Army. Journal of the American Osteopathic Association, 107(9), 401-407.

Leve, L. D., Kim, H. K., \& Pears, K. C. (2005). Childhood temperament and family environment as predictors of internalizing and externalizing trajectories from ages 5 to 17. Journal of Abnormal Child Psychology, 33(5), 505-520.

Maggs, J. L., Patrick, M. E., \& Feinstein, L. (2008). Childhood and adolescent predictors of alcohol use and problems in adolescence and adulthood in the National Child Development Study. Addiction, 103(Suppl. 1), 7-22.

Malow-Iroff, M. S. (2006). Cross-sex best friendship influences on early adolescent cigarette and alcohol expectancies and use. Journal of Psychology, 140(3), 209-227.

Moss, H. B., Vanyukov, M., Yao, J. K., \& Kirillova, G. P. (1999). Salivary cortisol responses in prepubertal boys: The effects of parental substance abuse and association with drug use behavior during adolescence. Biological Psychiatry, 45, 1293-1299.

National Institute on Alcohol Abuse and Alcoholism. (2008). FAQ for the general public. Retrieved October 1, 2008, from http://www.niaaa.nih .gov/FAQs/General-English/default.htm\#safe_level

Niemela, S., Sourander, A., Poikolainen, K., Helenius, H., Sillanmaki, L., Parkkola, K., . . . Moilanen, I. (2006). Childhood predictors of drunkenness in late adolescence among males: A 10-year population-based follow-up study. Addiction, 101(4), 512-521.

O’Donnell, J., Hawkins, J. D., \& Abbott, R. D. (1995). Predicting serious delinquency and substance use among aggressive boys. Journal of Consulting and Clinical Psychology, 63, 529-537.

Ohannessian, C. M., \& Hesselbrock, V. M. (2009). A finer examination of the role that negative affect plays in the relationship between paternal alcoholism and the onset of alcohol and marijuana use. Journal of Studies on Alcohol and Drugs, 70, 400-408.

Pitkanen, T., Kokko, K., Lyyra, A-L., \& Pulkkinen, L. (2008). A developmental approach to alcohol drinking behaviour in adulthood: A follow-up study from age 8 to age 42. Addiction, 103(Suppl. 1), 48-68.

Pritchard, C., \& Cox, M. (2007). Comparison of problematic behaviours of 10th and 11th year Southern English adolescents in 1985 and 2005. Part 1: Trends in gender behavior. International Journal of Adolescent Medicine and Health, 19(2), 127-140.

Radloff, L. S. (1977). The CES-D Scale: A self-report depression scale for research in the general population. Applied Psychological Measurement, 1(3), 385-401.

Reinherz, H., Giaconia, R., Hauf, A., Wasserman, M., \& Paradis, A. (2000). General and specific childhood risk factors for depression and drug disorders by early adulthood. Journal of the American Academy of Child \& Adolescent Psychiatry, 39(2), 223-231.

Rothbart, M. K., Ahadi, S. A., Hershey, K. L., \& Fisher, P. (2001) 
Investigations of temperament at three to seven years: The Children's Behavior Questionnaire. Child Development, 72(5), 1394-1408.

Schulenberg, J. E., \& Maggs, J. L. (2008). Destiny matters: Distal developmental influences on adult alcohol use and abuse. Addiction, 103(Suppl. 1), 1-6.

Silberg, J., Rutter, M., D’Onofrio, B., \& Eaves, J. L. (2003). Genetic and environmental risk factors in adolescent substance use. Journal of Child Psychology and Psychiatry, 44(5), 664-676.

Soderstrom, C. A., \& Dearing-Stuck, B. A. (1993). Substance misuse and trauma: Clinical issues and injury prevention. Adolescent Medicine, 4, 423-438.

Spielberger, C. D., Krasner, S. S., Solomon, E. P., \& Janisse, M. P. (1988). The experience, expression, and control of anger (pp. 89-108). New York: Springer Verlag/Publishers.

Spijkerman, R., van den Eijnden, R., J. J. M., \& Huiberts, A. (2008). Socioeconomic differences in alcohol-specific parenting practices and adolescents' drinking patterns. European Addiction Research, 14(1), 26-37.

Substance Abuse Mental Health Services Administration (2002). Summary of findings from the 2000 National Household Survey on Drug Abuse. Rockville, MD: Department of Health and Human Services.

Suldo, S. M., Mihalas, S., Powell, H., \& French, R. (2008). Ecological predictors of substance use in middle school students. School Psychology Quarterly, 23(3), 373-388.

Tarter, R. E., Blackson, T. C., Brigham, J., Moss, H. B., \& Caprara, G. V. (1995). The association between childhood irritability and liability to substance use in early adolescence: A 2-year follow-up study of boys at risk for substance use. Drug and Alcohol Dependence, 39, 253-261.

Tarter, R. E., \& Vanyukov, M. (1994). Alcoholism: A developmental disorder. Journal of Consulting and Clinical Psychology, 62(6), 10961107.

Tobler, A. L., Komro, K. A., \& Maldonado-Molina, M. M. (2009). Relationship between neighborhood context, family management practices and alcohol use among urban, multi-ethnic, young adolescents. Prevention Science, 10(4), 313-324.

Trim, R. S., \& Chassin, L. (2008). Neighborhood socioeconomic status effects on adolescent alcohol outcomes using growth models: Exploring the role of parental alcoholism. Journal of Studies on Alcohol and Drugs, 69(5), 639-648.

van der Vorst, H., Engels, R., Meeus, W., Dekovic, M., \& Vermulst, A. (2006). Parental attachment, parental control, and early development of alcohol use: A longitudinal study. Psychology of Addictive Behaviors, $20(2), 107-116$

Watson, D. (2009). Locating anger in the hierarchical structure of affect:
Comment on Carver and Harmon-Jones (2009). Psychological Bulletin, 135(2), 205-208.

Weissman, M. M., Wickramarante, P. J., Nomura, Y., Warner, V., Pilowsky, D., \& Verdeli, H. (2006). Offspring of depressed parents: 20 years later. American Journal of Psychiatry, 163(6), 1001-1008.

Williams, J. H., Van Dorn, R. A., Ayers, C. D., Bright, C. L., Abbot, R. D., $\&$ Hawkins, J. D. (2007). Understanding race and gender differences in delinquent acts and alcohol and marijuana use: A developmental analysis of initiation. Social Work Research, 31(2), 71-81.

Wills, T. A., Sandy, J. M., Shinar, O., \& Yaeger, A. (1999). Contributions of positive and negative affect to adolescent substance use: Test of a bidimensional model in a longitudinal study. Psychology of Addictive Behaviors, 13(4), 327-338.

Wills, T. A., Sandy, J. M., \& Yaeger, A. (2000). Temperament and adolescent substance use: An epigenetic approach to risk and protection. Journal of Personality, 68(6), 1127-1151.

Wills, T. A., Sandy, J. M., Yaeger, A., \& Shinar, O. (2001). Family risk factors and adolescent substance use: Moderation effects for temperament dimensions. Developmental Psychology, 37(3), 283-297.

Wills, T. A., \& Stoolmiller, M. (2002). The role of self-control in early escalation of substance use: A time-varying analysis. Journal of Consulting and Clinical Psychology, 70, 986-997.

Wilsnack, R. W., Vogeltanz, N. D., Wilsnack, S. C., \& Harris, T. R. (2000). Gender differences in alcohol consumption and adverse drinking consequences: Cross-cultural patterns. Addiction, 95(2), 251-265.

Wong, M. M., Nigg, J. T., Zucker, R. A., Puttler, L. I., Fitzgerald, H. E., Jester, J. M., . . Adams, K. (2006). Behavioral control and resiliency in the onset of alcohol and illicit drug use: A prospective study from preschool to adolescence. Child Development, 77(4), 1016-1033.

Wright, D., Sathe, N., \& Spagnola, K. (2007). State estimates of substance use from 2004-2005 National Surveys on Drug Use and Health (DHHS Publication No. SMA 07-4235, NSDUH Series H-31). Rockville, MD: Substance Abuse and Mental Health Services Administration, Office of Applied Studies.

Zahn-Waxler, C., Shirtcliff, E. A., \& Marceau, K. (2008). Disorders of childhood and adolescence: Gender and psychopathology. Annual Review of Clinical Psychology, 4, 275-303.

Zucker, R. A., Donovan, J. E., Masten, A. S., Mattson, M. E., \& Moss, H. B. (2008). Early developmental processes and the continuity of risk for underage drinking and problem drinking. Pediatrics, 121(Suppl. 4), S252-S272.

Received June 5, 2009

Revision received October 2, 2010 Accepted October 21, 2010 